\title{
$\mu$-Phenoxo- $\mu$-pseudohalide and $\mu$-pseudohalide dinuclear, tetranuclear and one-dimensional complexes: magneto-structural correlation and interesting type of solid state isomerism
}

\author{
SUJIT SASMAL and SASANKASEKHAR MOHANTA* \\ Department of Chemistry, University of Calcutta, 92, A P C Road, Kolkata 700 009, India \\ e-mail: sm_cu_chem@yahoo.co.in
}

\begin{abstract}
Five Schiff base ligands have been utilized to explore metallo-pseudohalide (azide or cyanate) systems. These ligands are the 1:1 condensation products of 3-methoxysalicylaldehyde with ethanolamine $\left(\mathrm{H}_{2} \mathrm{~L}^{1}\right) / 1$-(2-aminoethyl)-piperidine $\left(\mathrm{HL}^{2}\right) / 4$-(2-aminoethyl)-morpholine ( $\left.\mathrm{HL}^{3}\right)$ or salicylaldehyde with 1-(2-aminoethyl)-piperidine $\left(\mathrm{HL}^{4}\right) / 4$-(2-aminoethyl)-morpholine $\left(\mathrm{HL}^{5}\right)$. The derived complexes are as follows: Four heterobridged $\mu$-phenoxo- $\mu_{1,1}$-azide/cyanate dinickel(II) compounds of composition $\left[\mathrm{Ni}_{2}^{\mathrm{II}}\left(\mathrm{HL}^{1}\right)_{3}\left(\mu_{1,1}-\mathrm{N}_{3}\right)\right] \cdot 3 \mathrm{H}_{2} \mathrm{O}(\mathbf{1}),\left[\mathrm{Ni}_{2}^{\mathrm{II}}\left(\mathrm{L}^{2}\right)_{2}\left(\mu_{1,1}-\mathrm{N}_{3}\right)\left(\mathrm{N}_{3}\right)\left(\mathrm{H}_{2} \mathrm{O}\right)\right] \cdot \mathrm{CH}_{3} \mathrm{CH}_{2} \mathrm{OH}$ (2), [Ni $\mathrm{Ni}_{2}^{\mathrm{II}}\left(\mathrm{L}^{3}\right)_{2}-$ $\left.\left(\mu_{1,1}-\mathrm{N}_{3}\right)\left(\mathrm{CH}_{3} \mathrm{CN}\right)\left(\mathrm{H}_{2} \mathrm{O}\right)\right]\left(\mathrm{ClO}_{4}\right) \cdot \mathrm{H}_{2} \mathrm{O} \cdot \mathrm{CH}_{3} \mathrm{CN}(3)$ and $\left[\mathrm{Ni}_{2} \mathrm{II}^{\mathrm{II}}\left(\mathrm{HL}^{1}\right)_{3}\left(\mu_{1,1}-\mathrm{NCO}\right)\right] \cdot 2 \mathrm{H}_{2} \mathrm{O}$ (4); Two $\mu_{1,3}$-azide bridged tetranickel(II) compounds $\left[\left\{\mathrm{Ni}^{\mathrm{II}}\left(\mathrm{L}^{4}\right)\left(\mu_{1,3}-\mathrm{N}_{3}\right)\left(\mathrm{H}_{2} \mathrm{O}\right)\right\}_{4}\right](5)$ and $\left[\left\{\mathrm{Ni}^{\mathrm{II}}\left(\mathrm{L}^{5}\right)\left(\mu_{1,3}-\mathrm{N}_{3}\right)\left(\mathrm{H}_{2} \mathrm{O}\right)\right\}_{4}\right]$ (6); Two $\mu_{1,3}$-azide/cyanate one-dimensional compounds $\left[\mathrm{Cu}^{\mathrm{II}} \mathrm{L}^{5}\left(\mu_{1,3}-\mathrm{NCO}\right)\right]_{n} \cdot 2 n \mathrm{H}_{2} \mathrm{O}(7)$ and $\left[\mathrm{Cu}^{\mathrm{II}} \mathrm{L}^{5}\left(\mu_{1,3}-\mathrm{N}_{3}\right)\right]_{n}$. $2 n \mathrm{H}_{2} \mathrm{O}(\mathbf{8})$. Except compound 5 which shows overall antiferromagnetic coupling, other compounds exhibit overall ferromagnetic interaction. Syntheses, crystal structures, magnetic properties, density functional theoretical (DFT) calculations and experimental/theoretical magneto-structural correlations have been carried out which have revealed some interesting observations on composition/topology, magneto-structural correlations and solid state isomerism. The results have been already published. The present report deals with a review of the salient and interesting features of these works.
\end{abstract}

Keywords. Metallo-pseudohalides; magneto-structural correlations; DFT; heterobridged.

\section{Introduction}

Molecular magnetism is a frontier research area. ${ }^{1-5}$ One major focus in this area is to determine magnetostructural correlations, both experimental and theoretical. ${ }^{1-4}$ In an experimental correlation, $J$ versus one parameter (for example, bridge angle) relationship is determined for a few similar complexes. However, it is not possible to keep other governing parameters constant for these complexes, which may be considered as a limitation of experimental magneto-structural correlations. Therefore, it deserves importance if at least a pair of similar exchange-coupled systems are obtained for which all but one governing parameters are identical. On the other hand, at least for symmetrically bridged compounds, it is easily possible to change one governing parameter keeping others constant theoretically in the model systems and thus the effect of the change of other parameters is nullified in the theoretical correlations in symmetrically bridged systems. However, it is difficult to avoid the above mentioned limitation even in the theoretical correlations of

*For correspondence heterobridged systems (for example, $\mu$-phenoxo- $\mu_{1,1^{-}}$ azide dinuclear complexes) because it is not possible to change one parameter keeping all others constant (for example, the change of metal-phenoxo-metal angle is associated with change of metal-phenoxo distance in $\mu$ phenoxo- $\mu_{1,1}$-azide dinuclear complexes). Thus, determination of even the theoretical magneto-structural correlations in heterobridged systems deserves importance in molecular magnetism.

The research in structural chemistry focusing supramolecular chemistry/crystal engineering is another area which is being attracted vast fascination in recent years because of two major objectives of the self-assemblies: aesthetic beauty and possibility of being functional materials. ${ }^{6}$ Another perspective of solid state structural chemistry is to explore the little investigated types of isomerism as well as to find out new types of isomerism. Regarding nonclassical types of isomerism that have been developed in recent years, the following may be mentioned as examples: Jahn-Teller isomerism, ${ }^{7}$ supramolecular isomerism, ${ }^{8}$ molecular isomerism due to difference in number of interstitial solvent molecules, ${ }^{9}$ catenation isomerism. ${ }^{10}$ 


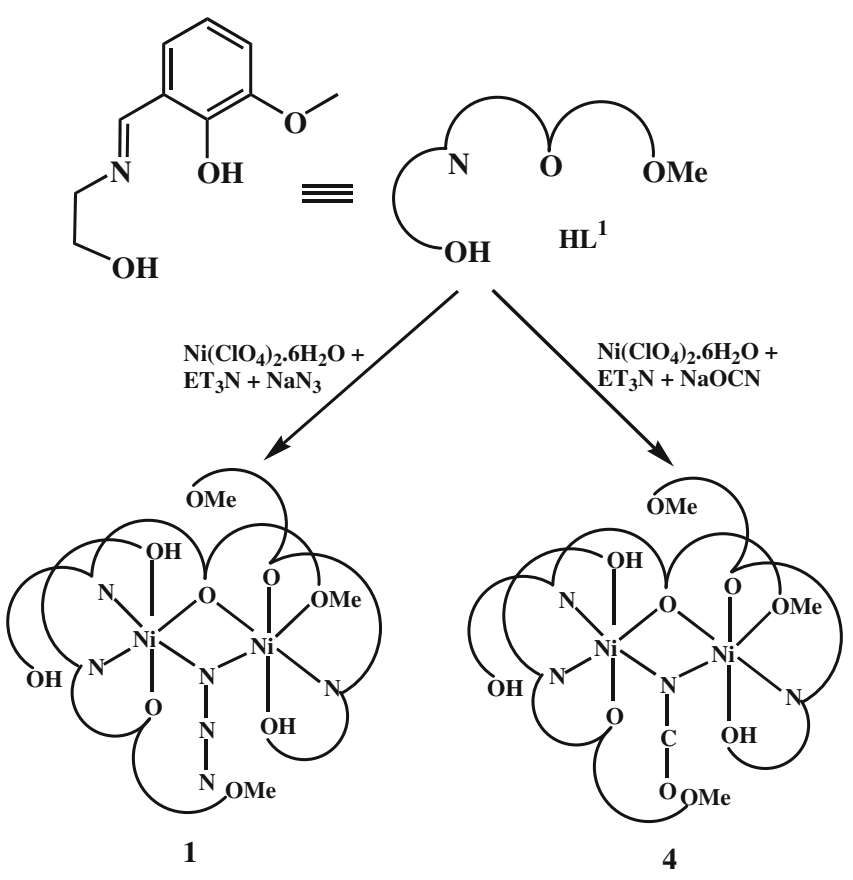

Scheme 1. Syntheses of 1 and 4 .
Metallo-pseudohalide, azide or cyanate, species have been always of great interest in molecular magnetism and supramolecular chemistry/crystal engineering due to a number of coordination modes of these potentially bridging ligands as well as due to their ability to mediate ferro or antiferromagnetic interactions among metal centres. The most usual bridging modes are the end-on $\left(\mu_{1,1^{-}} \text {, commonly expressed as EO }\right)^{1 \mathrm{a}, 1 \mathrm{~d}, 11-17}$ and end-to-end $\left(\mu_{1,3^{-}}, \mathrm{EE}\right),{ }^{1 \mathrm{a}, 1 \mathrm{~d}, 18,19}$ but some others like, $\mu_{1,1,1^{-},}{ }^{13,16,20,21} \mu_{1,1,3^{-},}{ }^{14,21} \mu_{1,1,1,1^{-},}{ }^{22}$ and $\mu_{1,1,3,3^{-}}{ }^{23}$ have been also described. This way, a number of azide/cyanate-bridged systems of different nuclearity (dinuclear, oligonuclear and polynuclear clusters) and also of 1D, 2D, and 3D topologies have been achieved and there is a considerable amount of information available on experimental and theoretical magneto-structural correlations. ${ }^{\text {1a, } 1 \mathrm{~d}, 11-23}$

Despite all the encouraging results, it is difficult to control the composition/topology of the metallopseudohalide species, which depends on factors like organic ligand, metal ion, solvent, stoichiometric ratio of reactants and other reaction conditions. To explore the metallo-pseudohalide species, we have

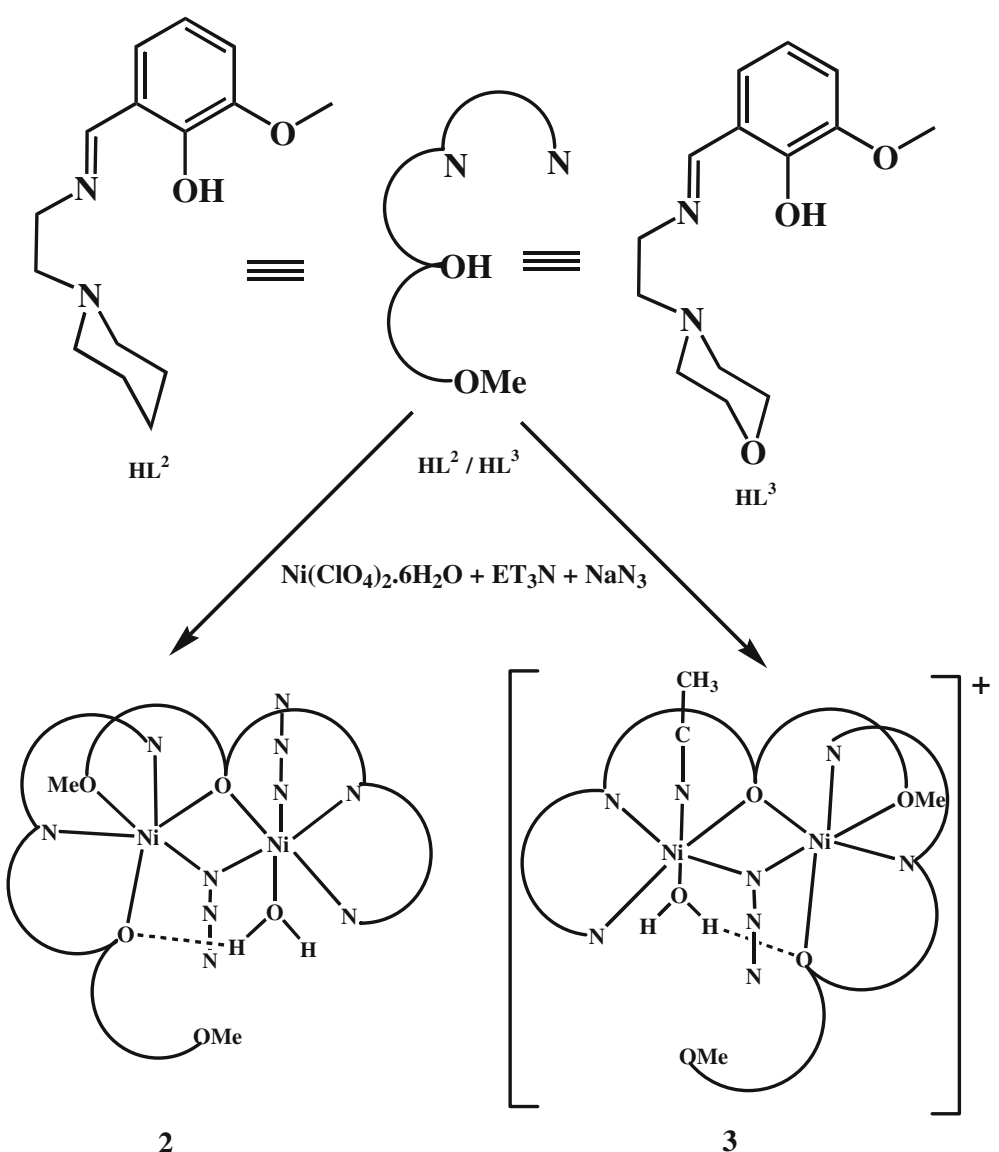

Scheme 2. Syntheses of $\mathbf{2}$ and $\mathbf{3}$. 
used five Schiff base ligands $\mathrm{H}_{2} \mathrm{~L}^{1}, \mathrm{HL}^{2}, \mathrm{HL}^{3}, \mathrm{HL}^{4}$ and $\mathrm{HL}^{5}$, which are the $[1+1]$ condensation products of 3-methoxysalicylaldehyde with ethanolamine (for $\mathrm{H}_{2} \mathrm{~L}^{1}$ ) / 1-(2-aminoethyl)-piperidine (for $\mathrm{HL}^{2}$ ) / 4-(2-aminoethyl)-morpholine (for $\mathrm{HL}^{3}$ ) or of salicylaldehyde with 1-(2-aminoethyl)-piperidine (for $\mathrm{HL}^{4}$ ) / 4-(2-aminoethyl)-morpholine (for $\mathrm{HL}^{5}$ ). We have synthesized the following compounds using these ligands: Four heterobridged $\mu$-phenoxo- $\mu_{1,1^{-}}$ azide/cyanate dinickel(II) compounds of composition $\left[\mathrm{Ni}_{2}^{\mathrm{II}}\left(\mathrm{HL}^{1}\right)_{3}\left(\mu_{1,1}-\mathrm{N}_{3}\right)\right] \cdot 3 \mathrm{H}_{2} \mathrm{O} \quad(\mathbf{1}), \quad\left[\mathrm{Ni}_{2}^{\mathrm{II}}\left(\mathrm{L}^{2}\right)_{2}\left(\mu_{1,1}-\mathrm{N}_{3}\right)\right.$ $\left.\left(\mathrm{N}_{3}\right)\left(\mathrm{H}_{2} \mathrm{O}\right)\right] \cdot \mathrm{CH}_{3} \mathrm{CH}_{2} \mathrm{OH} \quad$ (2), $\left[\mathrm{Ni}_{2}^{\mathrm{II}}\left(\mathrm{L}^{3}\right)_{2}\left(\mu_{1,1}-\mathrm{N}_{3}\right)\right.$ $\left.\left(\mathrm{CH}_{3} \mathrm{CN}\right)\left(\mathrm{H}_{2} \mathrm{O}\right)\right]\left(\mathrm{ClO}_{4}\right) \cdot \mathrm{H}_{2} \mathrm{O} \cdot \mathrm{CH}_{3} \mathrm{CN}$ (3) and $\left[\mathrm{Ni}_{2}^{\text {II }}\right.$ $\left.\left(\mathrm{HL}^{1}\right)_{3}\left(\mu_{1,1}-\mathrm{NCO}\right)\right] \cdot 2 \mathrm{H}_{2} \mathrm{O}$ (4); Two single end-toend azide bridged cyclic tetranickel(II) clusters of composition $\left[\left\{\mathrm{Ni}^{\mathrm{II}}\left(\mathrm{L}^{4}\right)\left(\mu_{1,3}-\mathrm{N}_{3}\right)\left(\mathrm{H}_{2} \mathrm{O}\right)\right\}_{4}\right] \quad$ (5) and $\left[\left\{\mathrm{Ni}^{\mathrm{II}}\left(\mathrm{L}^{5}\right)\left(\mu_{1,3}-\mathrm{N}_{3}\right)\left(\mathrm{H}_{2} \mathrm{O}\right)\right\}_{4}\right]$ (6); Two single end-toend azide/cyanate bridged one-dimensional copper(II) systems of composition $\left[\mathrm{Cu}^{\mathrm{II}} \mathrm{L}^{5}\left(\mu_{1,3}-\mathrm{NCO}\right)\right]_{n} \cdot 2 n \mathrm{H}_{2} \mathrm{O}$ (7), $\left[\mathrm{Cu}^{\mathrm{II}} \mathrm{L}^{5}\left(\mu_{1,3}-\mathrm{N}_{3}\right)\right]_{n} \cdot 2 n \mathrm{H}_{2} \mathrm{O}(\mathbf{8})$. Single crystal X-ray structure determination and variable-temperature/field magnetic studies have been done for all these eight

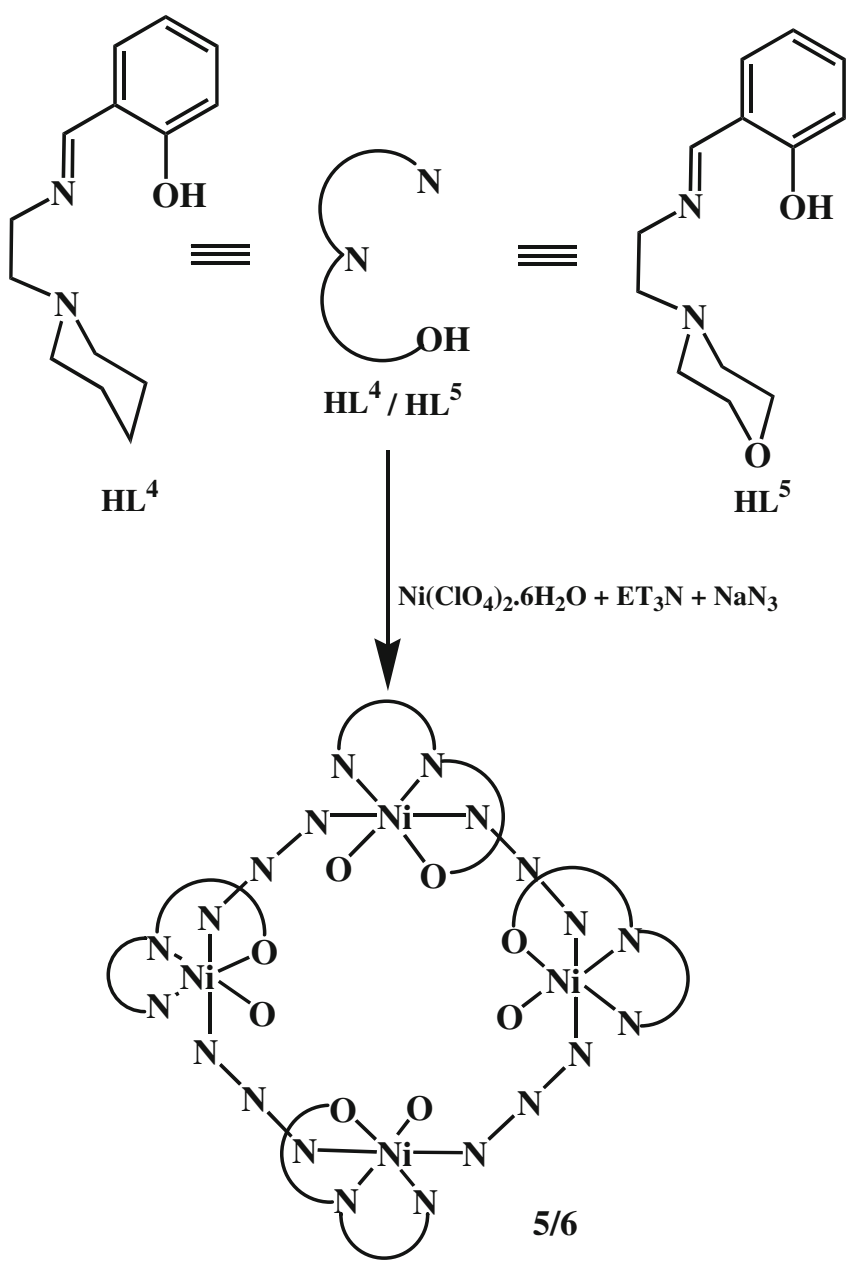

Scheme 3. Syntheses of 5 and $\mathbf{6}$.

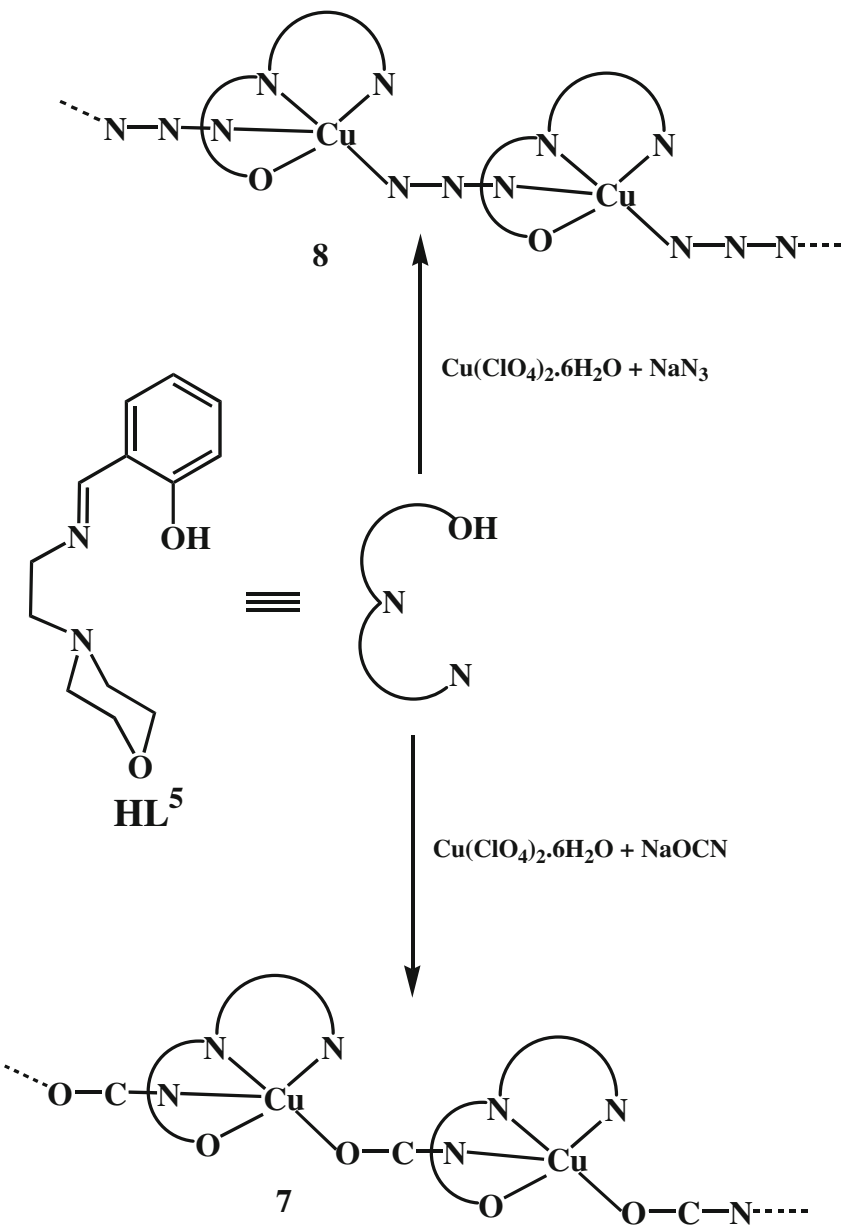

Scheme 4. Syntheses of $\mathbf{7}$ and 8.

compounds. Density functional theoretical calculations on magnetic properties have been carried out for 1-3, 5 and 6. Interesting experimental and theoretical magneto-structural correlations have been determined and new types of isomerism have been observed. The results have been already published. ${ }^{24-28}$ A review of the salient features of these works is being presented here.

\section{Outline of syntheses}

The dinickel(II) or tetranickel(II) complexes 1-6 are readily obtained in high yield from the reaction of the corresponding Schiff base ligand $\mathrm{H}_{2} \mathrm{~L}^{1 /}$ $\mathrm{HL}^{2} / \mathrm{HL}^{3} / \mathrm{HL}^{4} / \mathrm{HL}^{5}$, nickel(II) perchlorate hexahydrate, triethylamine and sodium azide/cyanate in 3:2:6:2 ratio (for $\mathbf{1}$ and $\mathbf{4}$ ) or in 1:1:1:4 ratio (for $\mathbf{2 , 3 , 5}$ and $\mathbf{6}$ ). For the copper(II) systems $\mathbf{7}$ and $\mathbf{8}$, the Schiff base: copper(II) perchlorate hexahydrate: sodium azide/cyanate ratio of 1:1:4 was used; the use of the base triethylamine was not required in these cases. The syntheses of the eight compounds are demonstrated in schemes 1, 2, 3 and 4. 
3. Crystal structures, and magneto-structural correlations of heterobridged $\mu$-phenoxo- $\mu_{1,1^{-}}$ azide/cyanate dinickel(II) compounds: Combined experimental and theoretical exploration ${ }^{24-26}$

Crystal structures of $\left.\mathrm{Ni}_{2}^{\mathrm{II}}\left(\mathrm{HL}^{1}\right)_{3}\left(\mu_{1,1}-\mathrm{N}_{3}\right)\right] \cdot 3 \mathrm{H}_{2} \mathrm{O}$ and $\left[\mathrm{Ni}_{2}^{\mathrm{II}}\left(\mathrm{L}^{2}\right)_{2}\left(\mu_{1,1}-\mathrm{N}_{3}\right)\left(\mathrm{N}_{3}\right)\left(\mathrm{H}_{2} \mathrm{O}\right)\right] \cdot \mathrm{CH}_{3} \mathrm{CH}_{2} \mathrm{OH}$ are shown in figures 1 and 2, while the crystal structures of $\left[\mathrm{Ni}_{2}^{\mathrm{II}}\left(\mathrm{L}^{3}\right)_{2}\left(\mu_{1,1}-\mathrm{N}_{3}\right)\left(\mathrm{CH}_{3} \mathrm{CN}\right)\left(\mathrm{H}_{2} \mathrm{O}\right)\right]\left(\mathrm{ClO}_{4}\right)$. $\mathrm{H}_{2} \mathrm{O} \cdot \mathrm{CH}_{3} \mathrm{CN}$ (3) and $\left[\mathrm{Ni}_{2}^{\mathrm{II}}\left(\mathrm{HL}^{1}\right)_{3}\left(\mu_{1,1}-\mathrm{NCO}\right)\right] \cdot 2 \mathrm{H}_{2} \mathrm{O}$ (4) are shown in figures $\mathrm{S} 1$ and $\mathrm{S} 2$ (supplementary informations). The structures reveal that $\mathbf{1 - 3}$ are $\mu$ phenoxo- $\mu_{1,1}$-azide dinickel(II) compounds, while $\mathbf{4}$ is a $\mu$-phenoxo- $\mu_{1,1}$-cyanate dinickel(II) compound.

The azide analogue $\mathbf{1}$ and the cyanate analogue $\mathbf{4}$ are derived from the same ligand and have similar type of structures containing three monodeprotonated ligands, $\left[\mathrm{HL}^{1}\right]^{-}$, in which the phenoxo moiety is deprotonated. Among the three phenolate oxygen atoms of three $\left[\mathrm{HL}^{1}\right]^{-}$, one bridges the two metal ions, while each of the remaining two is coordinated to each of the two metal ions in monodentate fashion. Of the three alcohol oxygen atoms, one is uncoordinated, while each of the other two coordinates to each of the two metal ions in monodentate fashion. Among the three imine

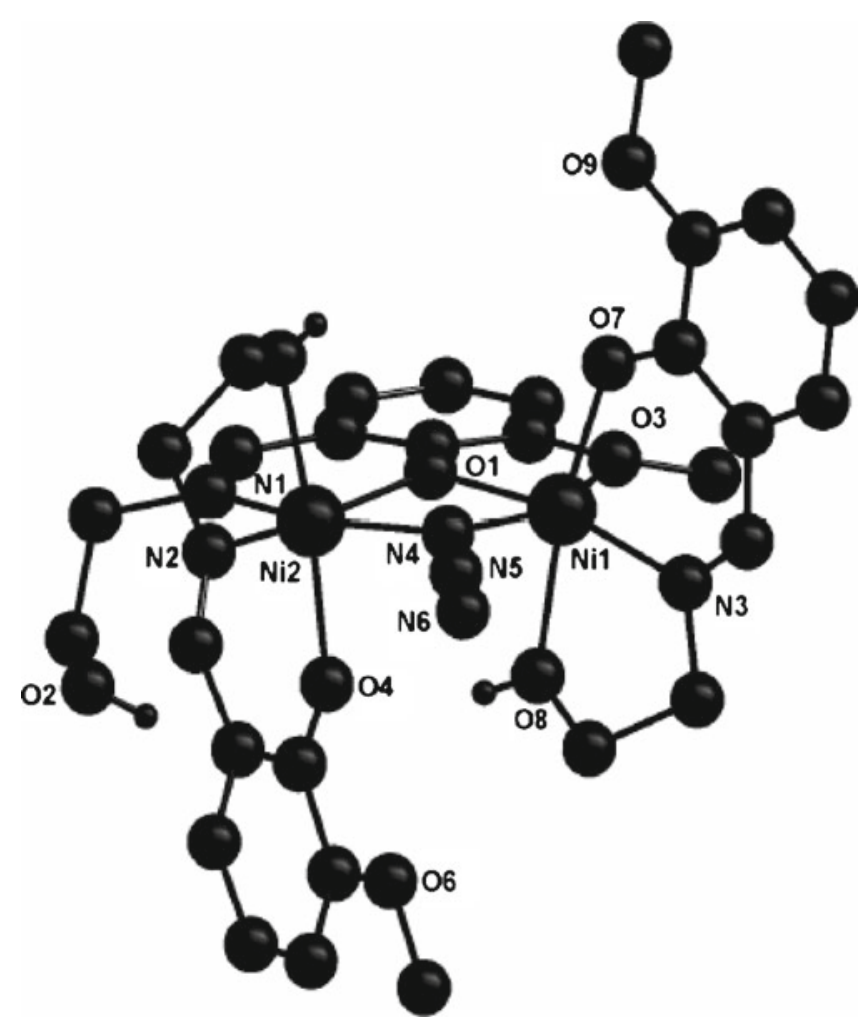

Figure 1. Crystal structure of $\left[\mathrm{Ni}_{2}^{\mathrm{II}}\left(\mathrm{HL}^{1}\right)_{3}\left(\mu_{1,1}-\mathrm{N}_{3}\right)\right] \cdot 3 \mathrm{H}_{2} \mathrm{O}$ (1). Hydrogen atoms, except of three alcohol moieties, and three water molecules are deleted for clarity. ${ }^{24,29}$

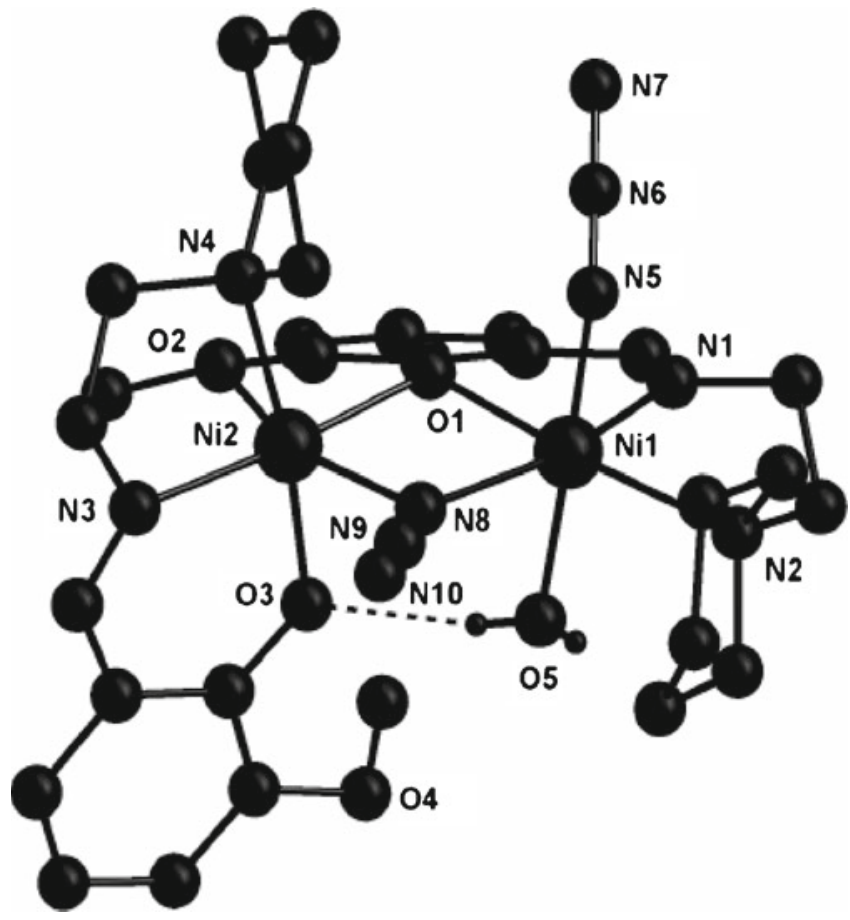

Figure 2. Crystal structure of $\left[\mathrm{Ni}_{2}^{\mathrm{II}}\left(\mathrm{L}^{2}\right)_{2}\left(\mu_{1,1}-\mathrm{N}_{3}\right)\left(\mathrm{N}_{3}\right)\right.$ $\left.\left(\mathrm{H}_{2} \mathrm{O}\right)\right] \cdot \mathrm{CH}_{3} \mathrm{CH}_{2} \mathrm{OH}(2)$. Hydrogen atoms, except those of water molecule, and solvated ethanol molecule are omitted for clarity. ${ }^{26,30}$

nitrogen atoms, two are coordinated to one metal ion, while the third coordinates to the second metal centre. Of the three ethereal oxygen atoms, one is coordinated to one metal ion, while the other two remain uncoordinated. In addition to the phenoxo bridge, the two metal centres are also bridged by the nitrogen atom of an end-on azide (in 1) or cyanate (in 4) ligand.

Compounds $\mathbf{2}$ and $\mathbf{3}$ contain two deprotonated ligands, $\left[\mathrm{L}^{2}\right]^{-} /\left[\mathrm{L}^{3}\right]^{-}$. While one of the two phenoxo oxygen atoms of two $\left[\mathrm{L}^{2}\right]^{-} /\left[\mathrm{L}^{3}\right]^{-}$bridges the two metal ions, the second phenoxo oxygen atom coordinates one metal ion. The two metal ions are additionally bridged by the nitrogen atom of an end-on azide ligand. Among the two methoxy oxygen atoms of two $\left[\mathrm{L}^{2}\right]^{-} /\left[\mathrm{L}^{3}\right]^{-}$, one is non-coordinated, while the second is coordinated to one metal centre. Each of the two metal ions are coordinated also to the imine and piperidine (for 2)/morpholine (for 3 ) nitrogen atoms of each of the two $\left[\mathrm{L}^{2}\right]^{-} /\left[\mathrm{L}^{3}\right]^{-}$.

Magnetic properties of the heterobridged $\mu$-phenoxo$\mu_{1,1}$-azide/cyanate dinickel(II) compounds $\mathbf{1 - 4}$ are shown in figures 3,4 , supplementary figures $\mathrm{S} 3$ and $\mathrm{S} 4$, respectively, as $\chi_{\mathrm{M}} T$ versus $T$ plots. The profiles indicate that the metal centres in all the four compounds are ferromagnetically coupled. Using the Hamiltonian $\mathbf{H}=-2 J\left(\mathbf{S}_{\mathbf{1}} \cdot \mathbf{S}_{\mathbf{2}}\right)+D_{1}\left[S_{Z, 1}^{2}\right]+D_{2}\left[S_{Z, 2}^{2}\right], \operatorname{good}$ 


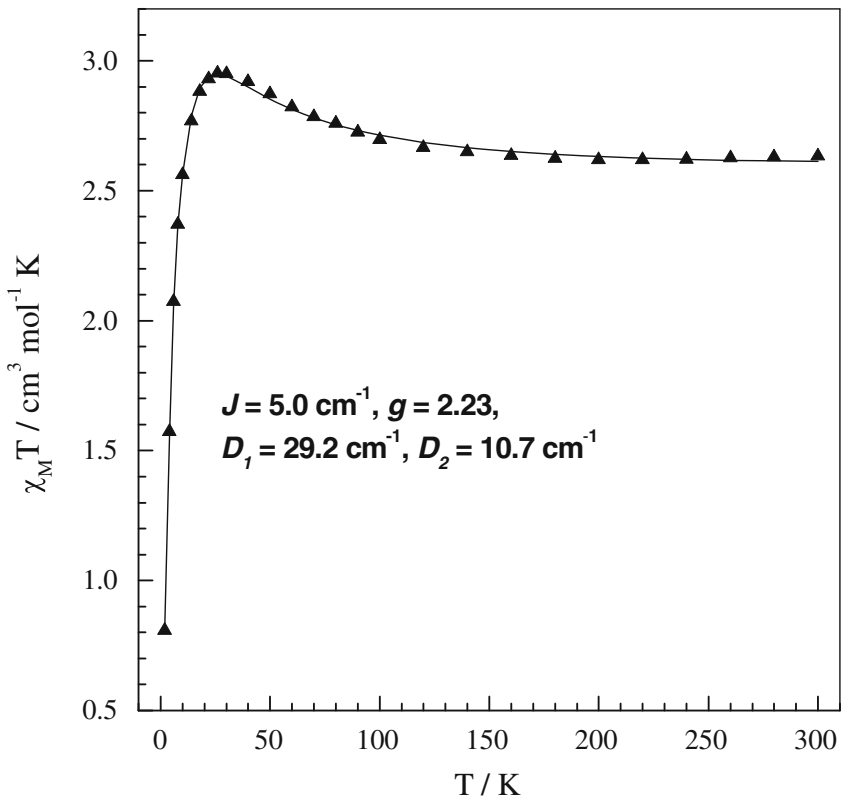

Figure 3. $\chi_{\mathrm{M}} T$ vs. $T$ plots for $\left[\mathrm{Ni}_{2}^{\mathrm{II}}\left(\mathrm{HL}^{1}\right)_{3}\left(\mu_{1,1}-\mathrm{N}_{3}\right)\right]$. $3 \mathrm{H}_{2} \mathrm{O}(\mathbf{1})$. Symbols and solid lines represent the observed and calculated data, respectively. ${ }^{24,29}$

quality simulations are obtained (figures 3, 4, supplementary figures $\mathrm{S} 3$ and $\mathrm{S} 4$ ) with following parameters: $J=5.0 \mathrm{~cm}^{-1}, g=2.23, D_{1}=29.2 \mathrm{~cm}^{-1}$ and $D_{2}=$ $10.7 \mathrm{~cm}^{-1}$ for $1 ; J=16.6 \mathrm{~cm}^{-1}, g=2.2$ and $D_{1}=$ $D_{2}=-7.3 \mathrm{~cm}^{-1}$ for $2 ; J=16.92 \mathrm{~cm}^{-1}, g=2.2$ and $D_{1}=D_{2}=-6.41 \mathrm{~cm}^{-1}$ for $3 ; J=3.33 \mathrm{~cm}^{-1}, g=2.24$ and $D_{1}=D_{2}=|6.68| \mathrm{cm}^{-1}$ for 4 .

Both the phenoxo and azide routes are responsible for the superexchange between the metal centres in a

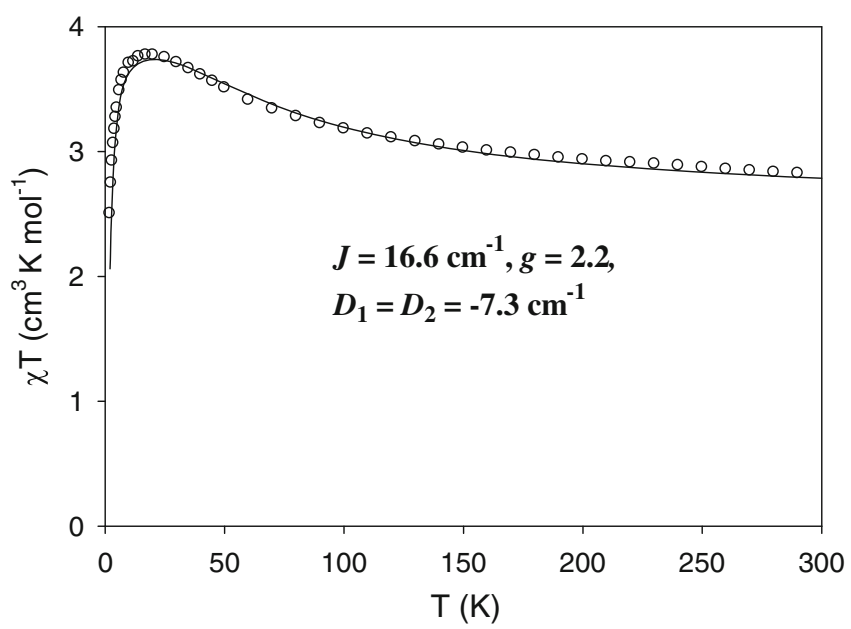

Figure 4. $\chi_{\mathrm{M}} T$ vs. $T$ plots for $\left[\mathrm{Ni}_{2}^{\mathrm{II}}\left(\mathrm{L}^{2}\right)_{2}\left(\mu_{1,1}-\mathrm{N}_{3}\right)\left(\mathrm{N}_{3}\right)\right.$ $\left.\left(\mathrm{H}_{2} \mathrm{O}\right)\right] \cdot \mathrm{CH}_{3} \mathrm{CH}_{2} \mathrm{OH}(2)$. Symbols and solid lines represent the observed and calculated data, respectively. ${ }^{26,30}$ heterobridged $\mu$-phenoxo- $\mu_{1,1}$-azide compound, such as 1-3. So, the nickel-azide-nickel and nickelphenoxo-nickel angles and two nickel-azide and two nickel-phenoxo distances should be the governing factors for the $J$ values in these compounds. Magnetic and structural parameters of the 1-3 and also of the only two previously reported $\mu$-phenoxo- $\mu_{1,1}$-azide dinickel(II) compounds are summarized in table 1.

For the two compounds $\mathbf{1}$ and IA (table 1), ${ }^{31 \mathrm{a}} \boldsymbol{J}$ values are drastically different; $5.0 \mathrm{~cm}^{-1}$ for $\mathbf{1}$ and $25.6 \mathrm{~cm}^{-1}$ for IA. Of the four governing parameters, the nickel-azide-nickel and nickel-phenoxo-nickel angles and both the nickel-phenoxo distances are practically identical for these two compounds. Only the nickelazide bond distances are different; 2.09 and $2.21 \AA$ for $\mathbf{1}$ and 2.13 and $2.15 \AA$ for IA. Clearly, the significant difference in the $J$ values arises due to difference in nickel-azide bridge distances. Thus, interestingly, these two compounds represent a unique pair for which all but one governing parameters are identical and also represent a unique pair demonstrating the bridge distance dependency of exchange integral. The asymmetry $(0.12 \AA$ in $\mathbf{1}, 0.02 \AA$ in $\mathbf{I A})$ in the two nickel-azide bond distances are greater in $\mathbf{1}$ than in IA. Thus, it seems that more the asymmetry in the two nickel-azide bond distances less the strength of ferromagnetic interaction. Such $J$ versus asymmetry correlation is also valid for compound 2 (table $1 ; J=16.6 \mathrm{~cm}^{-1}$, asymmetry $=0.06 \AA$ ), although other governing parameters of $\mathbf{2}$ are not identical with those of $\mathbf{1}$ or IA and thus the $J$ versus asymmetry correlation can be considered as more strengthened. On the other hand, the $J$ and asymmetry of compounds $\mathbf{3}$ and $\mathbf{I B}{ }^{31 b}$ are not in line with this correlation. So, it seems that although asymmetry in the two nickel-azide bond distances has some profound roles, the overall interaction is a composite effect of several parameters. Therefore, we have performed density functional theoretical calculations on the magnetic properties of 1-3 and IA. We have also determined theoretical magneto-structural correlations to get more insight regarding the role of the possible governing parameters, including asymmetry in the two nickel-azide bond distances.

Broken symmetry density functional calculations ${ }^{32}$ of exchange interaction provide good numerical estimate of $J$ values compared to experiments (table 1). Taking compound $\mathbf{2}$ as the model system, we have developed three different correlations. As mentioned in introduction section, the presence of dissimilar bridges prevents variation of only one structural parameter at a time to develop correlations. Therefore, we have defined three parameters $(\alpha, \beta$ and $\gamma)$ to vary two parameters (angles as well as the $\mathrm{Ni}-\mathrm{O}$ or $\mathrm{Ni}-\mathrm{N}$ 


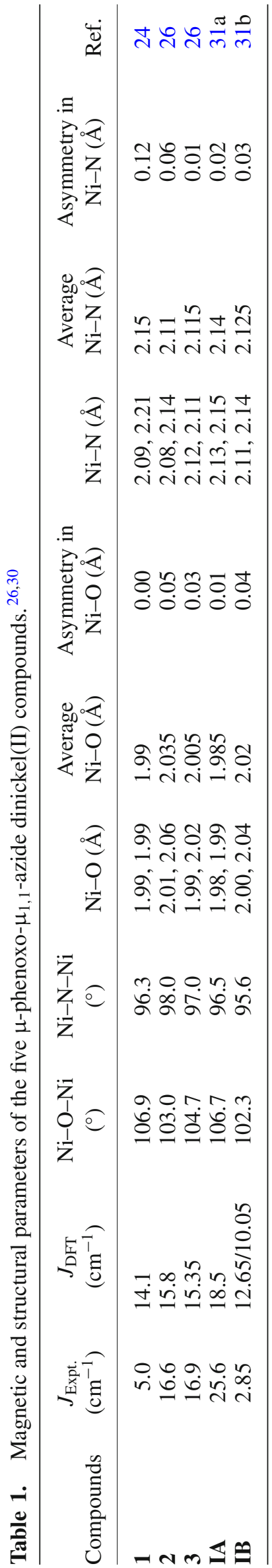

distances) at a time in our correlations. To underpin the role of asymmetry on the bond lengths, the asymmetry present in the bond distances were maintained same throughout.

\begin{tabular}{|l|l|l|}
\hline$\alpha=\frac{\mathrm{Ni}-\mathrm{O}-\mathrm{Ni}}{\mathrm{d}(\text { avg. } \mathrm{Ni}-\mathrm{O})}$ & $\boldsymbol{\beta}=\frac{\mathrm{Ni}-\mathrm{N}-\mathrm{Ni}}{\mathrm{d}(\text { avg. } \mathrm{Ni}-\mathrm{N})}$ & $\gamma=\frac{\mathrm{Ni}-\mathrm{N}-\mathrm{Ni}}{\mathrm{d}\left(\mathrm{Ni}_{\mathrm{B}}-\mathrm{N}\right)}$
\end{tabular}

According to the $J$ versus $\alpha$ correlation (figure S5), the magnitude of ferromagnetic $J$ is decreased with the increase of the $\mathrm{Ni}-\mathrm{O}-\mathrm{Ni}$ angle or the decrease of the $\mathrm{Ni}-\mathrm{O}$ distance. As shown in figure $\mathrm{S} 6$, the $J$ versus $\beta$ correlation indicates that the ferromagnetic interaction is increased as the nickel-azide-nickel angle increases or nickel-azide distance decreases, with a maximum at $\beta=106^{\circ}$. The $J$ versus $\gamma$ correlation (figure 5) reveals that ferromagnetic $J$ is increased with the increase of $\gamma$ to reach saturation at very large $\gamma$ values. To understand the dependency of $J$ on the asymmetry $(\Delta)$ in two nickel-azide distances, which is our major goal, the change in the $\mathrm{Ni}-\mathrm{N}-\mathrm{Ni}$ angle in the $J$ versus $\gamma$ correlation is ignored to get a $J$ versus asymmetry profile, as plotted in figure 6 . The asymmetry values in this graph are both positive and negative with reference to the fixed $\mathrm{Ni}_{\mathrm{A}}-\mathrm{N}$ distance of $2.082 \AA$. The asymmetry is negative when $\mathrm{d}_{\mathrm{NiB}-\mathrm{N}}>2.082 \AA$, while a positive asymmetry means $\mathrm{d}_{\mathrm{NiB}-\mathrm{N}}<2.082 \AA$. Although the shape of the curve in both the positive and negative asymmetry regions is closely linear, the role of asymmetry differs; while increase in negative asymmetry decreases the ferromagnetic interaction, increase in positive asymmetry increases the ferromagnetic interaction, albeit this saturates at larger value. As evident from this plot, if the $\mathrm{Ni}_{\mathrm{B}}-\mathrm{N}$ distance is larger than $2.082 \AA$ (i.e., if the asymmetry is negative), an increase in asymmetry will lead

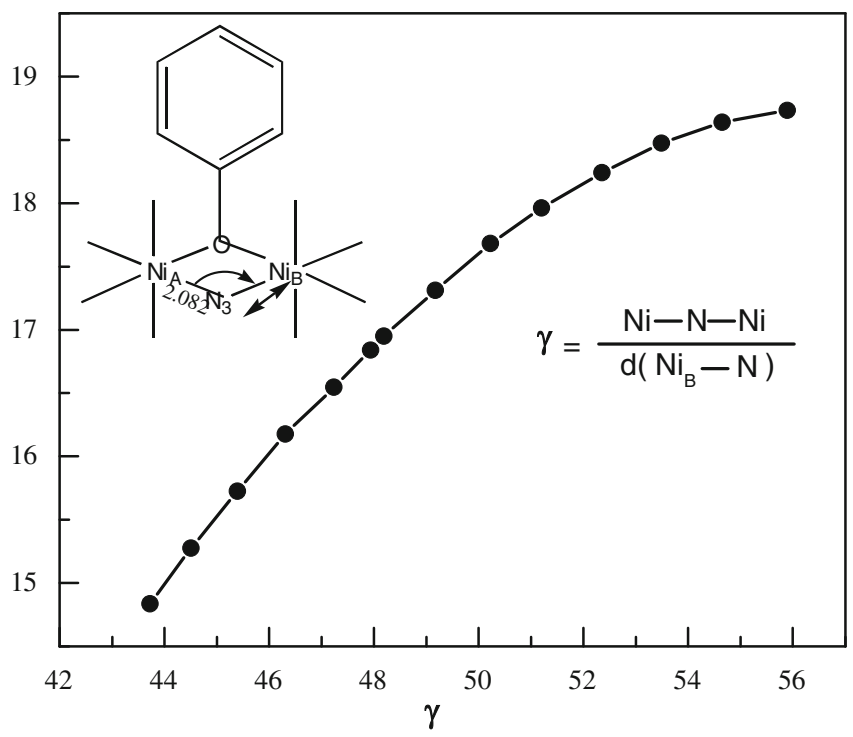

Figure 5. DFT-computed $J$ versus $\gamma$ correlation. ${ }^{26,30}$ 


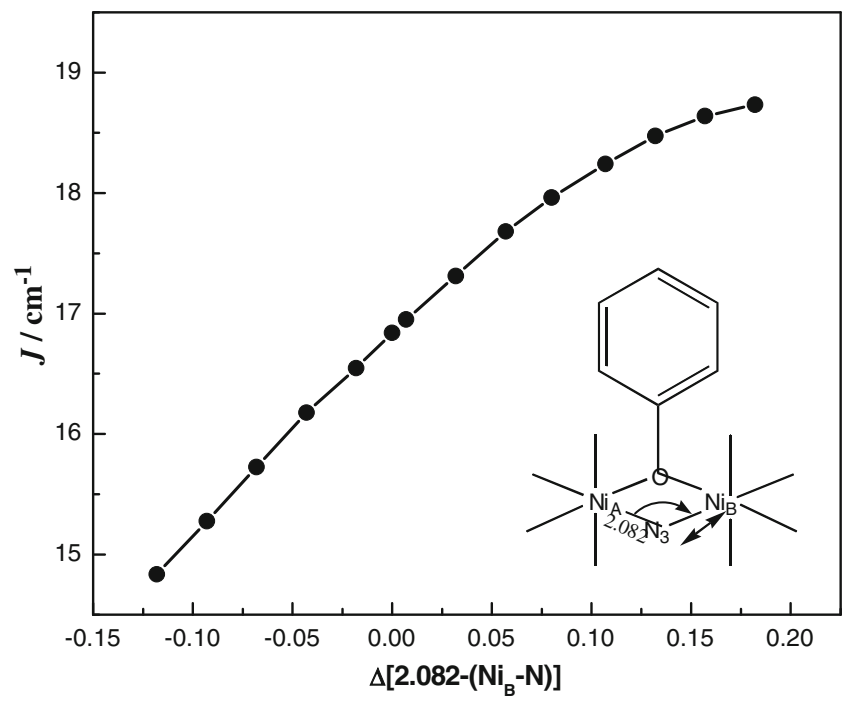

Figure 6. DFT-computed $J$ versus asymmetry in the two $\mathrm{Ni}-\mathrm{N}$ distances correlation (the variation in the $\mathrm{Ni}-\mathrm{N}-\mathrm{Ni}$ angle is ignored). ${ }^{26,30}$

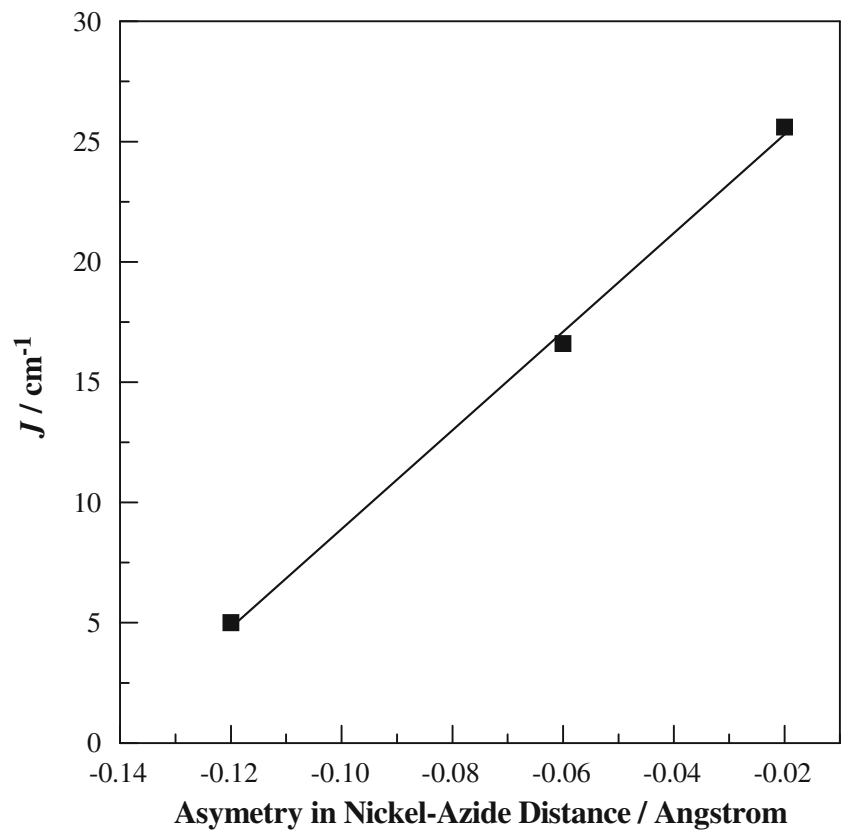

Figure 7. Linear magneto-structural correlation between experimental $J$ and asymmetry in two nickel-azide distances. ${ }^{26,30}$

to a smaller ferromagnetic $J$ and vice versa. In fact, such a trend (where $\Delta=$ shorter $\mathrm{Ni}-\mathrm{N}$ bond distance longer $\mathrm{Ni}-\mathrm{N}$ bond distance) has been observed experimentally in $\mathbf{1}\left(\Delta\right.$ is $-0.12 \AA$ and $\left.J=5.0 \mathrm{~cm}^{-1}\right), 2(\Delta$ is $-0.06 \AA$ and $\left.J=16.6 \mathrm{~cm}^{-1}\right)$ and IA $(\Delta$ is $-0.02 \AA$ and $\left.J=25.6 \mathrm{~cm}^{-1}\right)$; the linear magneto-structural correlation, on the basis of the experimental data of $\mathbf{1 , 2}$ and IA, between exchange integral and asymmetry is shown in figure 7 . Thus, asymmetry in the two nickelazide bond distances has been established both experimentally and theoretically as a major factor to govern the extent of ferromagnetic interaction in heterobridged $\mu$-phenoxo- $\mu_{1,1}$-azide dinickel(II) compounds.

\section{Crystal structures and magneto-structural correlation studies and theoretical calculations of a unique family of single end-to-end azide bridged $\mathrm{Ni}_{4}{ }_{4}$ cyclic clusters ${ }^{27}$}

The crystal structures of $\left[\left\{\mathrm{Ni}^{\mathrm{II}}\left(\mathrm{L}^{4}\right)\left(\mu_{1,3}-\mathrm{N}_{3}\right)\left(\mathrm{H}_{2} \mathrm{O}\right)\right\}_{4}\right]$ (5) and $\left[\left\{\mathrm{Ni}^{\mathrm{II}}\left(\mathrm{L}^{5}\right)\left(\mu_{1,3}-\mathrm{N}_{3}\right)\left(\mathrm{H}_{2} \mathrm{O}\right)\right\}_{4}\right](6)$ are shown in figures 8 and 9 . Overall, the structures of both species 5 and 6 can be described in a similar way; where all $\mathrm{Ni}^{\mathrm{II}}$ centres within each molecule are hexacoordinated and bounded to $\left[\mathrm{L}^{4}\right]^{-}$or $\left[\mathrm{L}^{5}\right]^{-}$through the phenoxo oxygen, imine and piperidine/morpholine nitrogen atoms of the corresponding ligand. The remaining coordination sites are satisfied by one molecule of $\mathrm{H}_{2} \mathrm{O}$ and two nitrogen atoms from $\mathrm{N}_{3}^{-}$anions. The latest act as bridges between $\mathrm{Ni}^{\mathrm{iI}}$ ions and eventually, only four azido groups are linked to the same number of $\mathrm{Ni}^{\mathrm{II}}$ centres resulting in the formation of cyclic $\left[\mathrm{Ni}_{4}^{\mathrm{II}}\right]$ systems. Interestingly, compounds 5 and $\mathbf{6}$ are the sole examples of tetranuclear clusters generated exclusively by end-to-end azide bridging ligands to date.

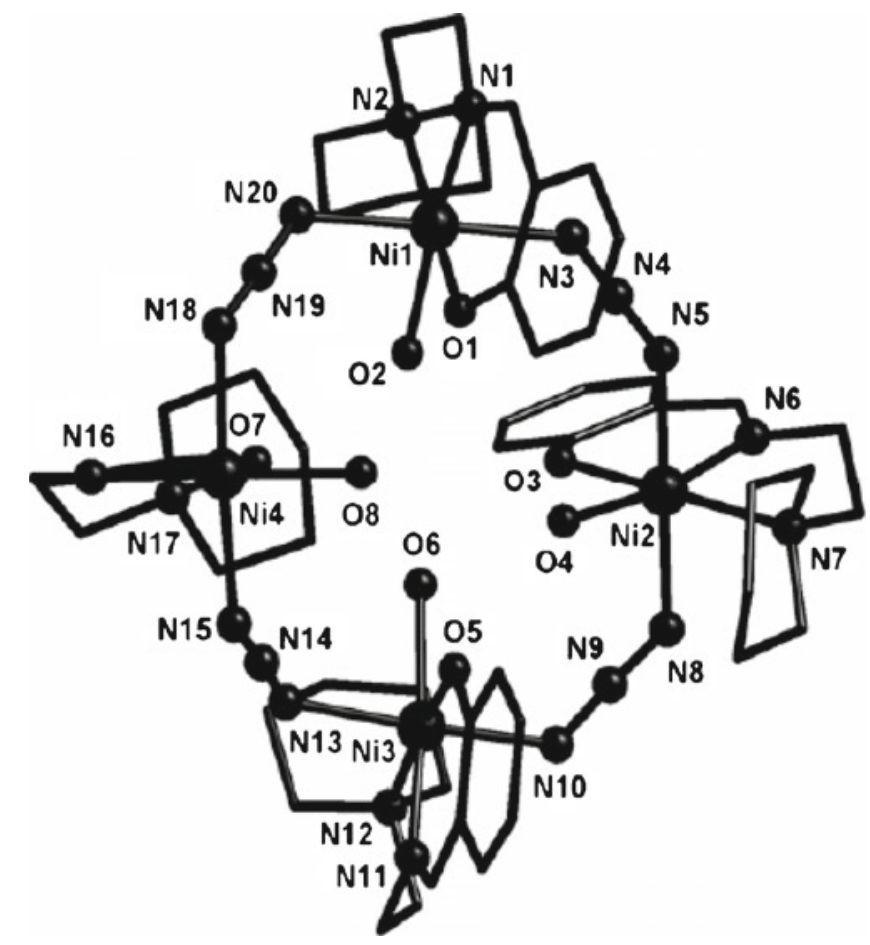

Figure 8. Crystal structure of $\left[\left\{\mathrm{Ni}^{\mathrm{II}}\left(\mathrm{L}^{4}\right)\left(\mu_{1,3}-\mathrm{N}_{3}\right)\left(\mathrm{H}_{2} \mathrm{O}\right)\right\}_{4}\right]$ (5). All the hydrogen atoms are omitted for clarity. ${ }^{27,33}$ 


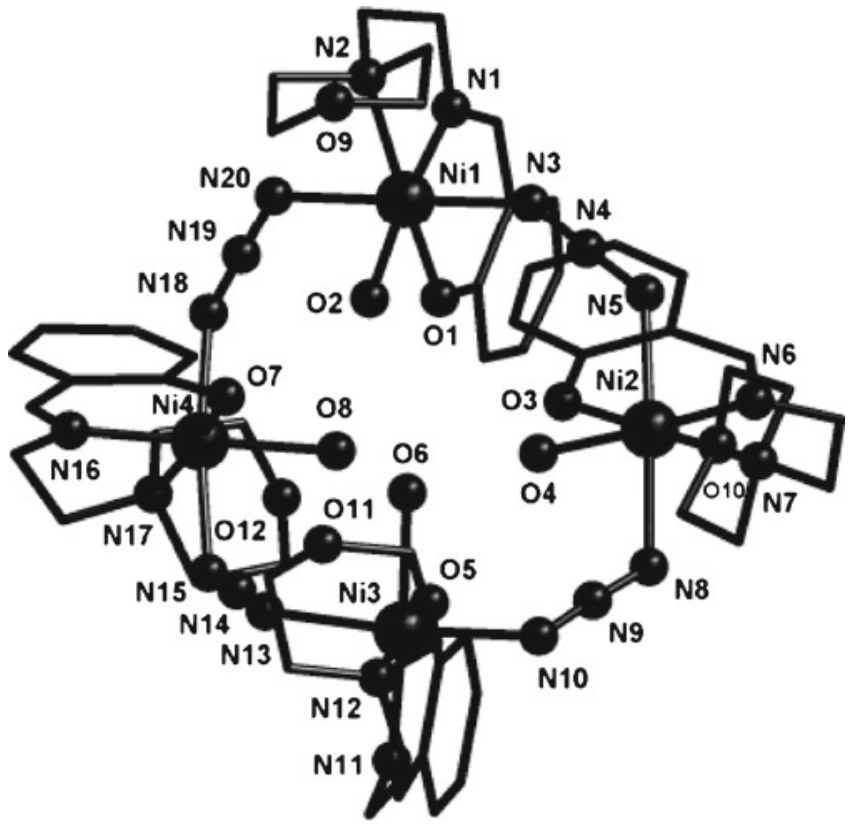

Figure 9. Crystal structure of $\left[\left\{\mathrm{Ni}^{\mathrm{II}}\left(\mathrm{L}^{5}\right)\left(\mu_{1,3}-\mathrm{N}_{3}\right)\left(\mathrm{H}_{2} \mathrm{O}\right)\right\}_{4}\right]$ (6). All the hydrogen atoms are omitted for clarity. ${ }^{27,33}$

The magnetic data of $\mathbf{5}$ and $\mathbf{6}$ are shown in figures 10 and 11 as $\chi_{\mathrm{M}} T$ versus $T$ plots. It is interesting that the magnetic behaviour of the two complexes is drastically different; Interaction is antiferromagnetic in one, $\mathbf{5}$, but ferromagnetic in the second, $\mathbf{6}$. For the end-toend azide bridged systems, two key parameters which govern the magnetic properties are $\mathrm{Ni}-\mathrm{N}-\mathrm{N}$ angles and $\mathrm{Ni}-\mathrm{N} \cdot \cdots \mathrm{N}-\mathrm{Ni}$ torsion angles, $\tau .^{1,18,19}$ Between these two, the Ni-N-N angles range almost similarly in the two complexes and so the difference in magnetic properties is expected to originate from the difference in the $\tau$ values: three types in $\mathbf{5}\left(87.5 / 90.6^{\circ}, 50.4^{\circ}\right.$ and $\left.3.3^{\circ}\right)$ but two types in $6\left(85.4 / 86.1^{\circ}\right.$ and $\left.54.7 / 57.8^{\circ}\right)$. It is known that the interaction should be antiferromagnetic if $\tau$ is $0^{\circ}$ and the antiferromagnetism decreases as $\tau$ increases from $0^{\circ}$ to $90^{\circ}$. Hence, compound $\mathbf{5}$ has an overall moderate antiferromagnetic behaviour due to the presence of an exchange pathway with an unprecedented $\mathrm{Ni}-\mathrm{N} \cdots \mathrm{N}-\mathrm{Ni}$ torsion angle $\left(3.3^{\circ}\right)$ close to $0^{\circ}$, while complex 6 exhibits a predominant ferromagnetic behaviour because the torsion angles in this case lie in between $\mathrm{ca} .50^{\circ}$ and $90^{\circ}$.

Depending on the types of the $\tau$ values, the magnetic data of $\mathbf{5}$ were modelled/fitted with three- $J$ Hamiltonian $\mathbf{H}=-2 J_{a}\left(\mathbf{S}_{\mathbf{1}} \cdot \mathbf{S}_{\mathbf{2}}+\mathbf{S}_{\mathbf{3}} \cdot \mathbf{S}_{\mathbf{4}}\right)-2 J_{b}\left(\mathbf{S}_{\mathbf{2}} \cdot \mathbf{S}_{\mathbf{3}}\right)$ $-2 J_{c}\left(\mathbf{S}_{\mathbf{4}} \cdot \mathbf{S}_{\mathbf{1}}\right)$, while the two- $J$ Hamiltonian $\mathbf{H}=$ $-2 J_{a}\left(\mathbf{S}_{\mathbf{1}} \cdot \mathbf{S}_{2}+\mathbf{S}_{\mathbf{3}} \cdot \mathbf{S}_{\mathbf{4}}\right)-2 J_{b}\left(\mathbf{S}_{\mathbf{2}} \cdot \mathbf{S}_{\mathbf{3}}+\mathbf{S}_{\mathbf{4}} \cdot \mathbf{S}_{\mathbf{1}}\right)$ are used for 6. The converging fitting parameters are listed in table 2. Importantly, $J=-35.25 \mathrm{~cm}^{-1}$ corresponding to $\tau=$ $3.3^{\circ}$ and is responsible for antiferromagnetism in $\mathbf{5}$.

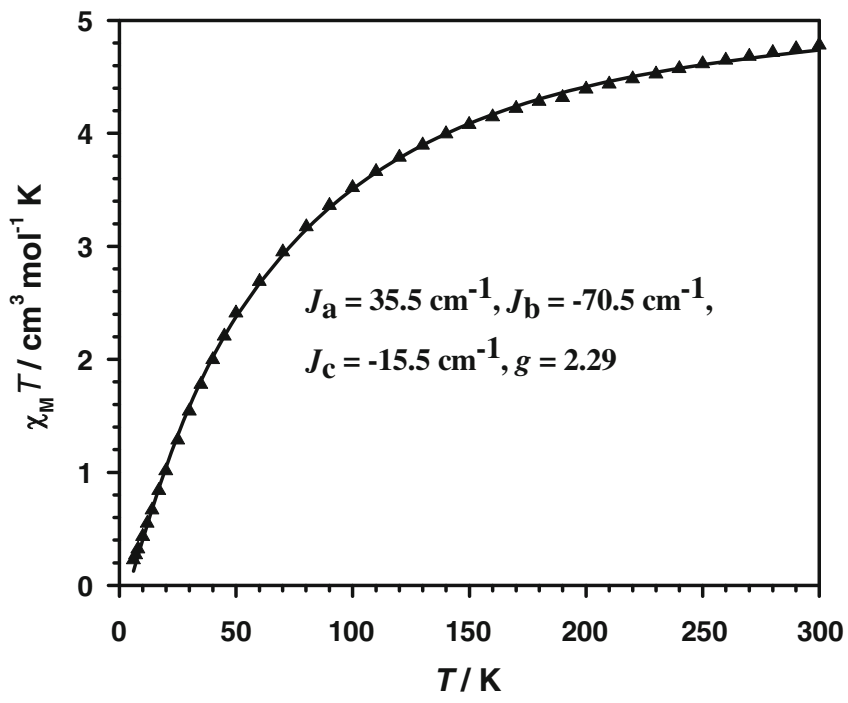

Figure 10. Observed (symbols) and calculated (solid lines) $\chi_{\mathrm{M}} T$ versus $T$ plots for $\left[\left\{\mathrm{Ni}^{\mathrm{II}}\left(\mathrm{L}^{4}\right)\left(\mu_{1,3}-\mathrm{N}_{3}\right)\left(\mathrm{H}_{2} \mathrm{O}\right)\right\}_{4}\right]$ (5). ${ }^{27,33}$

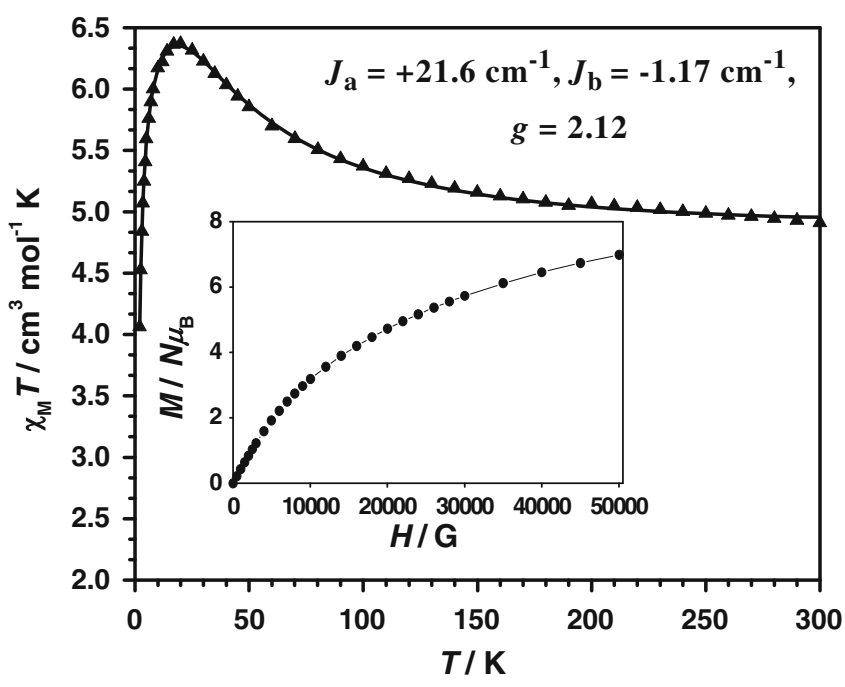

Figure 11. Observed (symbols) and calculated (solid lines) $\chi_{\mathrm{M}} T$ versus $T$ plots for $\left[\left\{\mathrm{Ni}^{\mathrm{II}}\left(\mathrm{L}^{5}\right)\left(\mu_{1,3}-\mathrm{N}_{3}\right)\left(\mathrm{H}_{2} \mathrm{O}\right)\right\}_{4}\right](6)$. The inset is an isothermal $M / N \mu_{B}$ vs. $H / G$ plot at $2.0 \mathrm{~K} .{ }^{27,33}$

To model the magnetic properties theoretically, density functional theoretical calculations ${ }^{36}$ have been performed on $\mathbf{5}$ and $\mathbf{6}$ with the four- $J$ Hamiltonian $\mathbf{H}=$ $-2 J_{12}\left(\mathbf{S}_{\mathbf{1}} \cdot \mathbf{S}_{\mathbf{2}}\right)-2 J_{\mathbf{2 3}}\left(\mathbf{S}_{\mathbf{2}} \cdot \mathbf{S}_{\mathbf{3}}\right)-2 J_{34}\left(\mathbf{S}_{\mathbf{3}} \cdot \mathbf{S}_{\mathbf{4}}\right)-2 J_{41}\left(\mathbf{S}_{\mathbf{4}} \cdot \mathbf{S}_{\mathbf{1}}\right)$. The theoretical $J$ values are compared with the experimental values in table 2 ; the trend is nicely matched. Interestingly, DFT-computed $J$ values reproduce the trend of the $\chi_{\mathrm{M}} T$ versus $T$ profile nicely (figure S7), indicating the ability of DFT methods in reproducing exchange Integrals. 
Table 2. Torsion angles and experimental and density functional theoretical $J$ values for single end-to-end azide bridged tetranickel(II) compounds $\mathbf{5}$ and $\mathbf{6}$.

\begin{tabular}{lcccc}
\hline $\mathrm{Ni}-\mathrm{N} \cdots \mathrm{N}-\mathrm{Ni}$ torsion angle $\left({ }^{\circ}\right)$ & $J(\mathrm{DFT}) / \mathrm{cm}^{-1}$ & $J($ Expt $) / \mathrm{cm}^{-1}$ \\
\hline Antiferromagnetic compound $\left[\left\{\mathrm{Ni}^{\mathrm{II}}\left(\mathrm{L}^{4}\right)\left(\mu_{1,3}-\mathrm{N}_{3}\right)\left(\mathrm{H}_{2} \mathrm{O}\right)\right\}_{4}\right](\mathbf{5})$ & & \\
90.6 & +7.45 & $J_{12}$ & +17.75 & $J_{a}$ \\
3.3 & -42.65 & $J_{23}$ & -35.25 & $J_{b}$ \\
87.5 & +8.55 & $J_{34}$ & +17.75 & $J_{a}$ \\
50.4 & -9.3 & $J_{41}$ & -7.75 & $J_{c}$ \\
Ferromagnetic compound $\left[\left\{\mathrm{Ni}^{\mathrm{II}}\left(\mathrm{L}^{5}\right)\left(\mu_{1,3}-\mathrm{N}_{3}\right)\left(\mathrm{H}_{2} \mathrm{O}\right)\right\}_{4}\right](\mathbf{6})$ & & \\
85.4 & +7.05 & $J_{12}$ & +10.8 & $J_{a}$ \\
54.7 & -2.25 & $J_{23}$ & -0.58 & $J_{b}$ \\
86.1 & +7.75 & $J_{34}$ & +10.8 & $J_{a}$ \\
57.8 & -0.6 & $J_{41}$ & -0.58 & $J_{b}$ \\
\hline
\end{tabular}

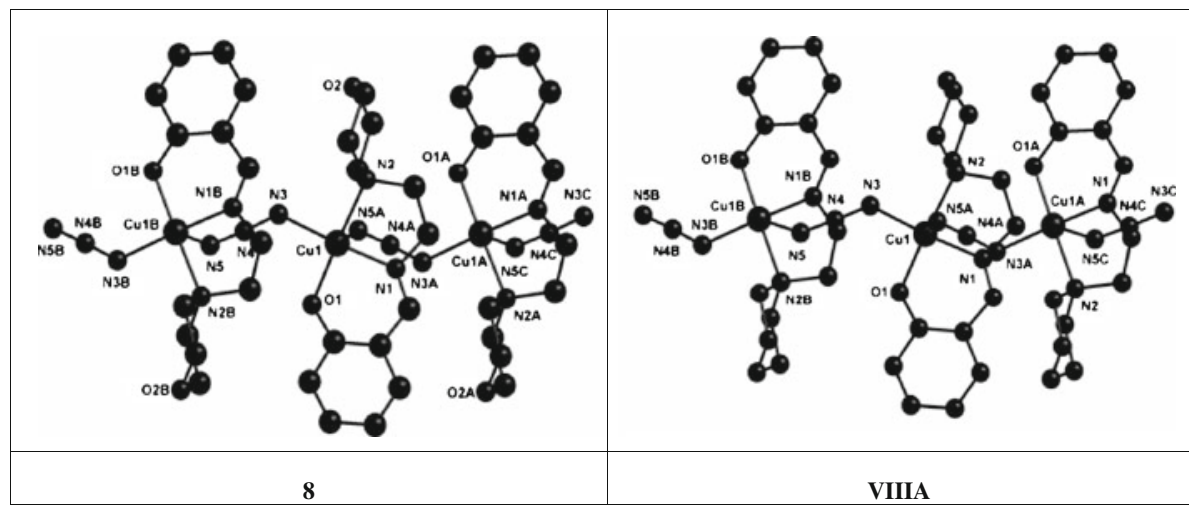

Figure 12. Crystal structures of $\left[\mathrm{Cu}^{\mathrm{II}} \mathrm{L}^{5}\left(\mu_{1,3}-\mathrm{N}_{3}\right)\right]_{n} \cdot 2 n \mathrm{H}_{2} \mathrm{O}(\mathbf{8})$ and $\left[\mathrm{Cu}^{\mathrm{II}} \mathrm{L}^{5}\left(\mu_{1,3^{-}}\right.\right.$ $\left.\left.\mathrm{N}_{3}\right)\right]_{n} \cdot 2 n \mathrm{H}_{2} \mathrm{O}$ (VIIIA). Hydrogen atoms and water molecules are not shown for clarity. Symmetry codes for 8: A, -x, -0.5+y, 0.5-z; B, -x, 0.5+y, 0.5-z; C, x, -1+y, z. Symmetry codes for VIIIA: A, 2-x, 0.5+y, 0.5-z; B, 2-x, $-0.5+y, 0.5-\mathrm{z} ; \mathrm{C}$, x, $\mathrm{y}-1, \mathrm{z}^{28,34,35}$

\section{Crystal structures and magnetic properties} of two one-dimensional end-to-end azide/cyanate bridged copper(II) compounds: new type of solid state isomerism $^{28}$

The perspective views of the end-to-end azide/ cyanate bridged one-dimensional copper(II) systems $\left[\mathrm{Cu}^{\mathrm{II}} \mathrm{L}^{5}\left(\mu_{1,3}-\mathrm{NCO}\right)\right]_{n} \cdot 2 n \mathrm{H}_{2} \mathrm{O}$ (7) and $\left[\mathrm{Cu}^{\mathrm{II}} \mathrm{L}^{5}\left(\mu_{1,3^{-}}\right.\right.$ $\left.\left.\mathrm{N}_{3}\right)\right]_{n} \cdot 2 n \mathrm{H}_{2} \mathrm{O}(8)$ are shown in figures $\mathrm{S} 8$ and $\mathrm{S} 12$, respectively. While the phenoxo oxygen atom and imine and morpholine nitrogen atoms of one deprotonated ligand, $\left[\mathrm{L}^{5}\right]^{-}$, satisfy the three coordination positions, the remaining two coordination positions of the pentacoordinated and distorted square pyramidal metal centre are satisfied by two nitrogen atoms of two end-to-end bridging azide ligands for $\mathbf{8}$ and by one nitrogen atom and one oxygen atom of two end-to-end bridging cyanate ligands for 7 .

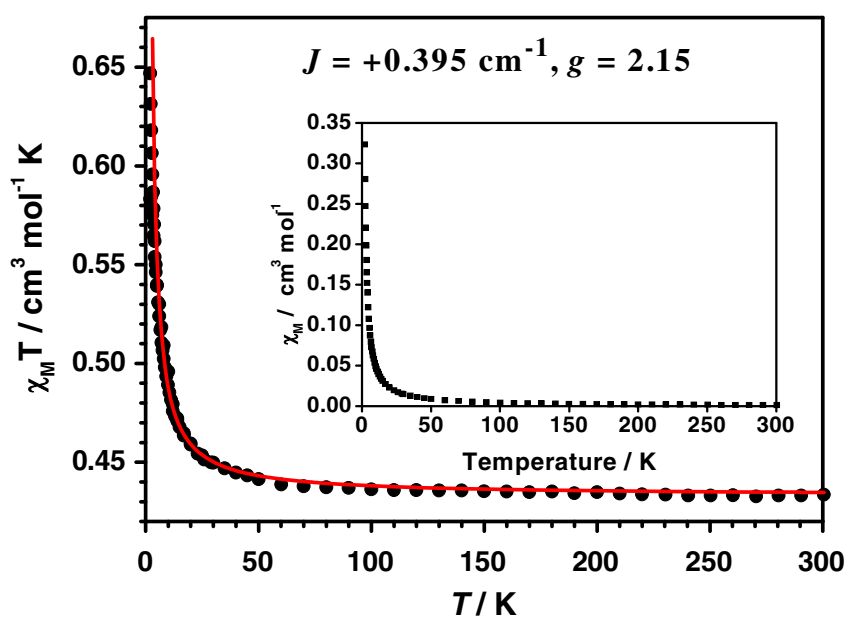

Figure 13. Fittings of the $\chi_{M} T$ vs. $T$ of $\left[\mathrm{Cu}^{\mathrm{II}} \mathrm{L}^{5}\left(\mu_{1,3^{-}}\right.\right.$ $\left.\left.\mathrm{N}_{3}\right)\right]_{n} \cdot 2 n \mathrm{H}_{2} \mathrm{O}(\mathbf{8})$ between 2.0 and $300.0 \mathrm{~K}$. The experimental data is shown as squares and the solid lines correspond to the theoretical values. Inset shows $\chi_{\mathrm{M}}$ vs. $T$ data. ${ }^{28,35}$ 
Table 3. Comparison of the crystallographic data of $\left[\mathrm{Cu}^{\mathrm{II}} \mathrm{L}^{5}\left(\mu_{1,3}-\mathrm{N}_{3}\right)\right]_{n} \cdot 2 n \mathrm{H}_{2} \mathrm{O} \quad(\mathbf{8})$ and $\left[\mathrm{Cu}^{\mathrm{II}} \mathrm{L}^{5}\left(\mu_{1,3}-\mathrm{N}_{3}\right)\right]_{n}$. $2 n \mathrm{H}_{2} \mathrm{O}$ (VIIIA).

\begin{tabular}{lll}
\hline & $\mathbf{8}$ & VIIIA \\
\hline Formula & $\mathrm{C}_{13} \mathrm{H}_{17} \mathrm{~N}_{5} \mathrm{O}_{4} \mathrm{Cu}^{a}$ & $\mathrm{C}_{13} \mathrm{H}_{21} \mathrm{~N}_{5} \mathrm{O}_{4} \mathrm{Cu}^{a}$ \\
Formula weight & $370.86^{a}$ & $374.90{ }^{a}$ \\
Crystal colour & Blue & Blue \\
Crystal system & Monoclinic & Monoclinic \\
Space group & $P 2{ }_{1} / c$ & $P 2{ }_{1} / c$ \\
$a, \AA$ & $9.4934(15)$ & $9.497(6)$ \\
$b, \AA$ & $9.2962(14)$ & $9.410(2)$ \\
$c, \AA$ & $18.377(3)$ & $18.232(8)$ \\
$V, \AA^{\circ}$ & $1606.4(4)$ & $1604.5(13)$ \\
$\alpha,{ }^{\circ}$ & 90.00 & 90.00 \\
$\beta,{ }^{\circ}$ & $97.902(2)$ & $100.01(3)$ \\
$\gamma,{ }^{\circ}$ & 90.00 & 90.00 \\
$Z$ & 4 & 4 \\
\hline
\end{tabular}

${ }^{a}$ Four water hydrogen atoms in $\mathbf{8}$ were not located. Actual formula and formula weight are same for both.

The magnetic data of $\mathbf{7}$ and $\mathbf{8}$ are shown in figure $\mathrm{S} 9$ and figure $13,{ }^{28,35}$ respectively, as $\chi_{\mathrm{M}} T$ versus $T$ plots. The profiles indicate the existence of ferromagnetic interaction in both the compounds. The magnetic data were fitted/modelled with the Hamiltonian $\mathbf{H}=-2 J \Sigma \mathbf{S A}_{\mathbf{i}} \cdot \mathbf{S A}_{\mathbf{i}+\mathbf{1}} \cdot{ }^{1 \mathrm{a}, 37}$ As shown by the solid lines in figure $\mathrm{S} 9$ and figure 13 , good quality fitting has been obtained with $J=+0.095 \mathrm{~cm}^{-1}$ and $g=2.13$ for the cyanate analogue 7 and $J=+0.395 \mathrm{~cm}^{-1}$ and $g=$ 2.15 for the azide analogue $\mathbf{8}$. It may be mentioned that compound $\mathbf{7}$ is the sole example of ferromagnetically coupled EE cyanate bridged 1-D copper(II) system.
Synthesis, crystal structure and magnetic properties of a compound $\left[\mathrm{Cu}^{\mathrm{II}} \mathrm{L}^{5}\left(\mu_{1,3}-\mathrm{N}_{3}\right)\right]_{n} \cdot 2 n \mathrm{H}_{2} \mathrm{O}$ (VIIIA) have been reported previously. ${ }^{34}$ Compound $\left[\mathrm{Cu}^{\mathrm{II}} \mathrm{L}^{5}\left(\mu_{1,3}-\mathrm{N}_{3}\right)\right]_{n} \cdot 2 n \mathrm{H}_{2} \mathrm{O} \quad$ (8) and $\left[\mathrm{Cu}^{\mathrm{II}} \mathrm{L}^{5}\left(\mu_{1,3^{-}}\right.\right.$ $\left.\left.\mathrm{N}_{3}\right)\right]_{n} \cdot 2 n \mathrm{H}_{2} \mathrm{O}$ (VIIIA) are derived from the same ligand $\left(\mathrm{HL}^{5}\right)$ and both have same composition. The azidebridged one-dimensional topology of both $\mathbf{8}$ and VIIIA are also same (figure 12). So, it may seem that $\mathbf{8}$ and VIIIA is the same compound. However, interestingly, the magnetic behaviour of $\mathbf{8}$ and VIIIA are drastically different; 8 exhibits ferromagnetic interaction with $J=+0.395 \mathrm{~cm}^{-1}$, while VIIIA exhibits antiferromagnetic interaction with $J=-2.15 \mathrm{~cm}^{-1}$. Thus, on the basis of the drastic difference in magnetic properties, it is clear that $\mathbf{8}$ and VIIIA is not the same compound but they are magnetic isomers. Interestingly, such type of magnetic isomerism is unprecedented. Now, comparison of the crystallographic data in table 3 reveals another interesting and unprecedented aspect: except $\beta$, other parameters are practically identical, revealing that this pair represents another new type of solid state isomerism which may be called crystallographic isomerism. Again, comparison of the structural parameters (table S1) indicates that some parameters are identical, while some others are different. On the basis of these similarities-dissimilarities of the structural parameters, the pair can also be called crystallographic isomerism. Now, let us look into the position of the two solvated water molecule in figure 14, revealing that positions of the water molecule are different. Moreover, the number/types of hydrogen bonds and overall supramolecular structures are also different; 8 is threedimensional (figures S10 and S11), while VIIIA is

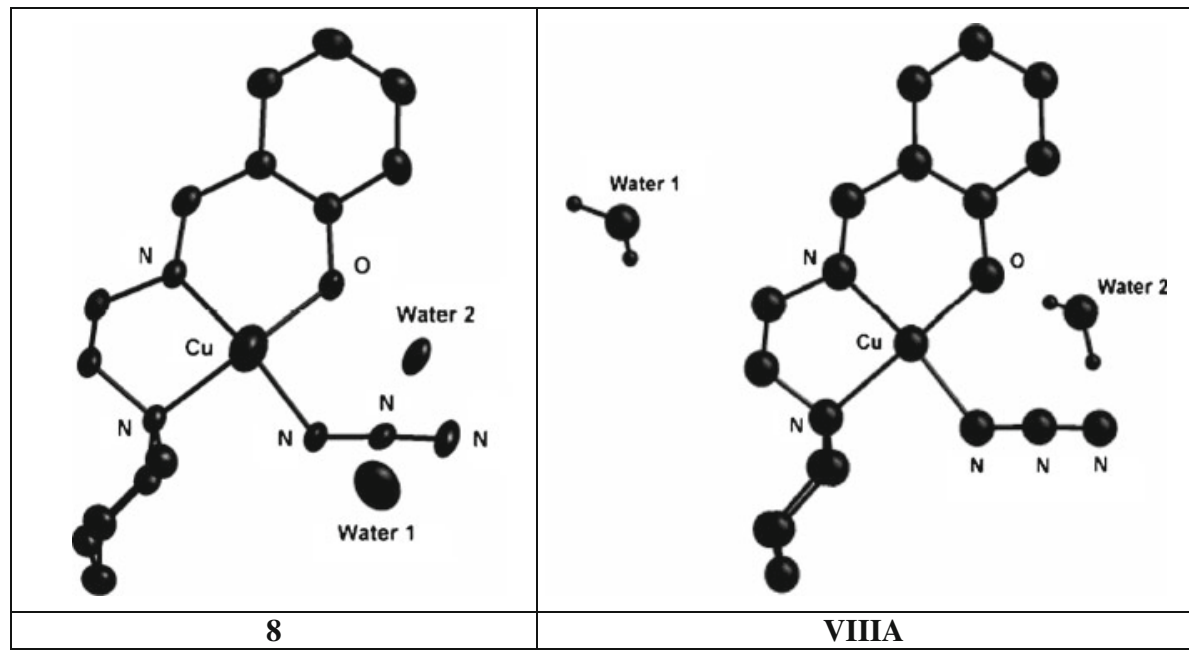

Figure 14. Perspective views in almost same orientation of $\left[\mathrm{Cu}^{\mathrm{II}} \mathrm{L}^{5}\left(\mu_{1,3-}\right.\right.$ $\left.\left.\mathrm{N}_{3}\right)\right]_{n} \cdot 2 n \mathrm{H}_{2} \mathrm{O}(\mathbf{8})$ and $\left[\mathrm{Cu}^{\mathrm{II}} \mathrm{L}^{5}\left(\mu_{1,3}-\mathrm{N}_{3}\right)\right]_{n} \cdot 2 n \mathrm{H}_{2} \mathrm{O}$ (VIIIA) demonstrating the difference in location of the two solvated water molecule in the two structures. ${ }^{28,34,35}$ 
two-dimensional (figure S12). Thus, 8 and VIIIA also represent rare example of supramolecular isomerism.

\section{Conclusions}

The outcome of the research work reviewed here can be summarized as follows: (i) unique observation of a pair of compounds for which all but one parameters, governing magnetic exchange interaction, are identical; (ii) unique example of bridge distance dependency of exchange integral; (iii) rare determination of several density functional theoretical magneto-structural correlations in heterobridged systems; (iv) profound role of asymmetry in the two nickel-azide bond distances in governing the exchange integral in heterobridged $\mu$-phenoxo- $\mu_{1,1}$-azide dinickel(II) systems, as obtained both experimentally and theoretically; (v) unique examples of only single end-to-end azide bridged tetranuclear complexes; (vi) observation of unprecedented small value, $3.3^{\circ}$, of $\mathrm{Ni}-\mathrm{N} \cdots \mathrm{N}-\mathrm{Ni}$ torsion angle; (vii) demonstration of overall antiferromagnetic interaction in one single end-to-end azide bridged $\mathrm{Ni}_{4}^{\mathrm{II}}$ system and overall ferromagnetic interaction in the second similar system as the function of the $\mathrm{Ni}-\mathrm{N} \cdots \mathrm{N}-\mathrm{Ni}$ torsion angles; (viii) reasonable/excellent matching of the DFT-computed and experimental $J$ values; (ix) nice matching of the trends of the experimental $\chi_{M} T$ data with the $\chi_{M} T$ data obtained from the DFT-computed $J$ values; (x) first example of a ferromagnetically coupled end-to-end cyanate bridged one-dimensional copper(II) system; (xi) a unique pair representing new type of magnetic isomerism, new type of crystallographic isomerism and rare type of supramolecular isomerism.

\section{Supplementary material}

Figures S1-S12 and table $\mathrm{S} 1$ are available at http://www.ias.ac.in/chemsci.

\section{Acknowledgements}

Financial support from Government of India through the Department of Science and Technology (DST) (Project to SM) and the University Grants Commission (Fellowship to SS) are gratefully acknowledged.

\section{References}

1. (a) Kahn O 1993 In Molecular magnetism; New York: VCH; (b) Willet R D, Gatteschi D, Kahn O (eds) 1985 Magneto-structural correlations in exchange coupled systems; Dordrecht, The Netherlands: Reidel; (c)
O'Connor C J (ed.) 1993 Research frontiers in magnetochemistry; World Scientific: Singapore; (d) Ribas J, Escuer A, Monfort M, Vicent R, Cortés R, Lezam L and Rojo T 1999 Coord. Chem. Rev. 1931027

2. (a) Thompson L K, Mandal S K, Tandon S S, Bridson J N and Park M K 1996 Inorg. Chem. 35 3117; (b) Nanda K K, Thompson L K, Bridson J N and Nag K 1994 Chem. Commun. 1337; (c) Mohanta S, Nanda K K, Thompson L K, Flörke U and Nag K 1998 Inorg. Chem. 37 1465; (d) Chaudhuri P, Wagner R, Khanra S and Weyhermuller T 2006 Dalton Trans. 4962

3. (a) Palacios M A, Mota A J, Perea-Buceta J E, White F J, Brechin E K and Colacio E 2010 Inorg. Chem. 49 10156; (b) Halcrow M A, Sun J S, Huffman J C and Christou G 1995 Inorg. Chem. 344167

4. (a) Ruiz E, Cano J, Alvarez S and Alemany P 1998 J. Am. Chem. Soc. 120 11122; (b) Ruiz E, Alemany P, Alvarez S and Cano J 1997 J. Am. Chem. Soc. 119 1297; (c) Cauchy T, Ruiz E and Alvarez S 2006 J. Am. Chem. Soc. 128 15722; (d) Manca G, Cano J and Ruiz E 2009 Inorg. Chem. 48 3139; (e) Triki S, Gómez-García C J, Ruiz E and Sala-Pala J 2005 Inorg. Chem. 455501

5. (a) Winpenny R, (ed) 2006 Single-molecule magnets and related phenomena; Springer: New York; (b) Miller J S, Drillon M, (eds) 2001 Magnetism: Molecules to materials II; Willey-VCH: Weinheim

6. (a) Beer P D and Gale P A 2001 Angew. Chem. Int. Ed. 40 486; (b) Lehn J-M 1995 In Supramolecular chemistry; Weinheim: VCH, (c) Robson R 2000 Dalton Trans. 3735; (d) Sauvage J-P, Ed. 1999 Transition metals in supramolecular chemistry; Perspectives in supramolecular chemistry, London: Wiley, Vol. 5; (e) Blake A J, Champness N R, Hubberstey P, Withersby M A and Schröder M 1999 Coord. Chem. Rev. 183 117; (f) Lin H-H, Mohanta S, Lee C-J and Wei H-H 2003 Inorg. Chem. 42 1584; (g) Nayak M, Koner R, Lin H-H, Flörke U, Wei H-H and Mohanta S 2006 Inorg. Chem. 45 10764; (h) Hazra S, Koner R, Nayak M, Sparkes H A, Howard J A K and Mohanta S 2009 Cryst. Growth Des. 9 3603; (i) Nayak M, Jana A, Fleck M, Hazra S and Mohanta S 2010 Cryst. Eng. Commun. 12 1416; (j) Sasmal S, Majumder S, Hazra S, Sparkes H A, Howard J A K, Nayak M and Mohanta S 2010 Cryst. Eng. Commun. 124131

7. Awaga K, Suzuki Y, Hachisuka H and Takeda K 2006 J. Mater. Chem. 262516

8. (a) Ring D J, Aragoni M C, Champness N R and Wilson C 2005 Cryst. Eng. Commun. 7 621; (b) Zhang J-P and Kitagawa S 2008 J. Am. Chem. Soc. 130907

9. Poulsen R D, Overgaard J, Schulman A, Østergaard C, Murillo C A, Spackman M A and Iversen B B 2009 J. Am. Chem. Soc. 1317580

10. Ma L and Lin W 2008 J. Am. Chem. Soc. 13013834

11. (a) Feng P L, Stephenson C J, Amjad A, Ogawa G, Barco E d and Hendrickson D N 2010 Inorg. Chem. 49 1304; (b) Clemente-Juan J M, Mackiewicz C, Verelst M, Dahan F, Bousseksou A, Sanakis Y and Tuchagues J-P 2002 Inorg. Chem. 411478

12. Demeshko S, Leibeling G, Dechert S and Meyer F 2006 Dalton Trans. 3458

13. Milios C J, Prescimone A, Sanchez-Benitez J, Parsons S, Murrie M and Brechin E K 2006 Inorg. Chem. 457053 
14. Demeshko S, Leibeling G, Maringgele W, Meyer F, Mennerich C, Klauss H-H and Pritzkow H 2005 Inorg. Chem. 44519

15. Liu G-F, Ren Z-G, Li H-X, Chen Y, Li Q-H, Zhang Y and Lang J-P 2007 Eur. J. Inorg. Chem. 5511

16. Zhang Y-Z, Wernsdorfer W, Pan F, Wang Z-M and Gao S 2006 Chem. Commun. 3302

17. Gu Z-G, Song Y, Zuo J-L and You X-Z 2007 Inorg. Chem. 469522

18. (a) Hong C S, Koo J-E, Son S-K, Lee Y S, Kim Y-S and Do Y 2001 Chem.-Eur. J. 7 4243; (b) Vicente R, Escuer A, Peñalba E, Solans X and Font-Bardía M 1994 J. Chem. Soc., Dalton Trans. 3005

19. (a) Goher M A S, Escuer A, Mautne F A and Al-Salem N A 2002 Polyhedron 21 1871; (b) Escuer A,Vicente R, Ribas J, Fallah M S E and Solans X 1993 Inorg. Chem. 32 1033; (c) Liu X-T, Wang X-Y, Zhang W-X, Cui P and Gao S 2006 Adv. Mater. 18 2852; (d) Monfort M, Resino I, Ribas J, Solans X, Font-Bardía M and Stoeckli-Evans H 2002 New J. Chem. 261601

20. Stamatatos T C, Abboud K A, Wernsdorfer W and Christou G 2006 Angew. Chem. Int. Ed. 454134

21. (a) Bell A, Aromí G, Teat S J, Wernsdorfer W and Winpenny R E P 2005 Chem. Commun. 2808; (b) Luo J, Zhou X-G, Weng L-H and Hou X-F 2003 Acta Crystallogr., Sec. C: Cryst. Struct. Commun. 59 m519

22. (a) Papaefstathiou G S, Perlepes S P, Escuer A, Vicente R, Font-Bardía M and Solans X 2001 Angew.Chem., Int. Ed. 40 884; (b) Boudalis A K, Sanakis Y, ClementeJuan J M, Donnadieu B, Nastopoulos V, Mari A, Coppel Y, Tuchagues J-P and Perlepes S P 2008 Chem.-Eur. J. 142514

23. Meyer F, Kircher P and Pritzkow H 2003 Chem. Commun. 774

24. Koner R, Hazra S, Fleck M, Jana A, Lucas C R and Mohanta S 2009 Eur. J. Inorg. Chem. 4982

25. Hazra S, Koner R, Lemoine P, Sañudo E C and Mohanta S 2009 Eur. J. Inorg. Chem. 3458

26. Sasmal S, Hazra S, Kundu P, Dutta S, Rajaraman G, Sañudo E C and Mohanta S 2011 Inorg. Chem. 50 7257

27. Sasmal S, Hazra S, Kundu P, Majumder S, AliagaAlcalde N, Ruiz E, Mohanta S 2010 Inorg. Chem. 49 9517
28. Sasmal S, Sarkar S, Aliaga-Alcalde N and Mohanta S 2011 Inorg. Chem. 505687

29. Figures 1 and 3 in this article are redrawn in comparison to the figures 1 and 3 in ref. 24. Copyright Wiley$\mathrm{VCH}$ Verlag $\mathrm{GmbH} \& \mathrm{Co}$. KGaA. Reproduced with permission.

30. Figures 2 and 7 in this article are redrawn in comparison to the figures 1 and 12 in ref. 26. Figures 4, 5 and 6 and table 1 in this article are adapted after slight redrawing/modification of the figures 3,10 and 11 and table 3 in ref. 26. Copyright American Chemical Society. Reprinted (adapted) with permission.

31. (a) Dey S K, Mondal N, Fallah M S E, Vicente R, Escuer A, Solans X, Font-Bardía M, Matsushita T, Gramlich V and Mitra S 2004 Inorg. Chem. 43 2427; (b) Banerjee A, Singh R, Chopra D, Colacio E and Rajak K K 2008 Dalton Trans. 6539

32. The Noodleman's BS approach; B3LYP exchangecorrelation functional; valence triple-zeta quality basis sets (TZV) of Ahlrichs and coworkers; GAUSSIAN 03 suite of programs with an initial guess made using Jaguar 7.0

33. Figures 8 and 9 in this article are redrawn in comparison to the figures 1 and 2 in ref. 27. Figures 10 and 11 in this article are adapted after slight redrawing/modification of the figures 3 and 4 in ref. 27. Copyright American Chemical Society. Reprinted (adapted) with permission.

34. Mukherjee P S, Dalai S, Mostafa G, Lu T-H, Rentschler E and Chaudhuri N R 2001 New J. Chem. 251203

35. A part of figure 12 (for compound 8 ) and figure 14 in this article are redrawn in comparison to the figures 2 and S9 in ref. 28. Figure 13 in this article is adapted after slight redrawing/modification of the figure 4 in ref. 28. Copyright American Chemical Society. Reprinted (adapted) with permission. Another part of figure 12 (for compound VIIIA) is drawn taking CIF from the Cambridge Structural Database (Version 5.32, 2011), the Cambridge Crystallographic Data Centre.

36. B3LYP exchange-correlation functional; basis set of triple- $\zeta$ quality as proposed by Schaefer et al; Gaussian09 code using guess functions generated with the Jaguar 7.0 code

37. Baker G A, Rushbrooke G S and Guilbert H E 1964 Phys. Rev. 135 A 1272 